\title{
USOS DA AUTOCONFRONTAÇÃO NA LINGUÍSTICA APLICADA: O CASO DE UM GRUPO DE PESQUISA
}

\author{
USES OF SELF-CONFRONTATION IN THE APPLIED \\ LINGUISTIC: THE CASE OF A RESEARCH GROUP
}

\author{
Deivis Perez* \\ Carla Messias
}

\section{RESUMO}

Este artigo discute o uso do dispositivo interventivo e científico-metodológico autoconfrontação por pesquisadores da Linguística Aplicada, em particular, pelos estudiosos do grupo de pesquisa Análise de Linguagem, Trabalho Educacional e suas Relações-ALTER que desenvolveram as suas atividades entre os anos de 2002 e 2012, sob a liderança da professora doutora Anna Rachel Machado da Pontifícia Universidade Católica de São Paulo/PUC-SP. O artigo apresenta a autoconfrontação, as suas origens, as referências teóricas, as fases e os movimentos que devem ser seguidos na sua aplicação. Em seguida, buscou-se examinar o uso da autoconfrontação em teses de doutorado e dissertações de mestrado produzidas no contexto do grupo ALTER. Ao final, são focalizadas as limitações na utilização do dispositivo verificadas nas pesquisas do grupo e também o seu significativo legado para a Linguística Aplicada e para as Ciências do Trabalho no Brasil.

Palavras-chave: metodologia de pesquisa, linguística aplicada, Clínica da Atividade.

\section{ABSTRACT}

This article is about the use of the methodological procedure called selfconfrontation by researchers from Applied Linguistics especially by the scholars from the research group Language Analysis, Educational Work and their relationships/ALTER, which developed its activities from 2002 to 2012, under the leadership of the professor doctor Anna Rachel Machado from PUC-SP. The article shows a selfconfrontation, its origins, theoretical references, phases and movements that must be followed in the use of this procedure. Afterwards, the use of the selfconfrontation was examined and discussed through doctoral and masters' theses produced by ALTER context. Finally, the limitations of the procedure application identified in the group researches and their meaning left to Applied Linguistic and the Work Sciences are presented.

Keywords: research methodology, applied linguistic, Clinic Activity.

* UNESP, Assis (SP), Brasil. prof.deivisperez@hotmail.com; Secretaria de Estado da Educação de Mato Grosso, Cuibá (MT). chrckln2010@hotmail.com 


\section{INTRODUÇÃO}

Este artigo discute as aplicações do dispositivo autoconfrontação em pesquisas que resultaram na produção de dissertações de mestrado e teses de doutorado realizadas no Brasil por pesquisadores do campo da Linguística Aplicada. Optou-se por debater a temática geral proposta por intermédio do exame do caso particular de utilização da autoconfrontação pelos estudiosos do grupo Análise de Linguagem, Trabalho Educacional e suas Relações (doravante, nomeado ALTER) que desenvolveram as suas atividades entre 2002 e 2012, sob a liderança da professora doutora Anna Rachel Machado, e era vinculado institucionalmente ao Programa de Pós-Graduação em Linguística Aplicada e Estudos da Linguagem da Pontifícia Universidade Católica de São Paulo (LAEL/PUC-SP). O dispositivo ao qual referimos é especificamente aquele que foi criado pelo linguista Faïta (1997) e aperfeiçoado no quadro teórico-metodológico da Clínica da Atividade (VIEIRA e FAÏTA, 2003; CLOT, 2006; 2010).

É relevante mencionar, inicialmente, que este artigo é o resultado do processo de aprofundamento do exame e contextualização para a realidade brasileira de dispositivos metodológicos de intervenção e investigação científica realizados pelo grupo de pesquisa Figuras e Modo de Subjetivação no Contemporâneo, vinculado ao Programa de Pós-Graduação em Psicologia da Universidade Estadual Paulista Júlio de Mesquita Filho (UNESP) - câmpus Assis, certificado pelo Conselho Nacional de Desenvolvimento Tecnológico e Científico (CNPq). Neste momento, está em andamento, com o apoio da Fundação de Amparo à Pesquisa do Estado de São Paulo (FAPESP), o exame dos usos por pesquisadores brasileiros do dispositivo denominado instrução ao sósia, que foi criado nos anos 1970 por Odonne (1981) e, analogamente a autoconfrontação, tem sido aperfeiçoado desde meados dos anos 1990 no contexto da Clínica da Atividade. Ainda, cumpre destacar que anteriormente foi feita a investigação dos modos de utilização da autoconfrontação em pesquisas exclusivamente sobre o trabalho de professores que resultaram na conclusão de dissertações e teses de programas de pós-graduação das áreas de Educação e Linguística Aplicada (MESSIAS, PEREZ, 2013a; 2013b). Nos estudos já concluídos, foram identificados e analisados trinta e oito pesquisas que fizeram uso da autoconfrontação para examinar o trabalho docente no período que se estendeu entre 1987 e 2011.

A autoconfrontação, objeto de nosso interesse, se caracteriza como um dispositivo interventivo e de investigação dos processos de trabalho que contribui para fazer emergir os múltiplos discursos e perspectivas em torno de um ofício 
determinado, integrando o analista do trabalho ou pesquisador e os trabalhadores, de modo a favorecer a instalação de um movimento dialético de análise e produção de saberes sobre o trabalho, a apropriação destes saberes pelo coletivo de trabalhadores e a modificação ou aperfeiçoamento da atividade laboral. Isso ocorre porque o procedimento de autoconfrontação serve como elemento que auxilia o planejamento e a organização da sucessão de ações voltadas para a aproximação e modificação do fenômeno laborativo, que inclui: sua análise, sua compreensão e sua metamorfose pelos próprios trabalhadores, com o apoio do especialista ou pesquisador.

$\mathrm{Na}$ Clínica da Atividade, a investigação do trabalho com o uso da autoconfrontação tem dois pressupostos básicos, a saber: o primeiro diz respeito à demanda por exame do trabalho que deve emergir de um grupo de profissionais que percebeu que o exercício das suas funções ocupacionais se encontra degradado (CLOT, 2010). Assim, o analista ou pesquisador do trabalho deve ser convidado por um coletivo de trabalhadores para contribuir na mediação do processo de (re) apropriação das atividades de ofício pelos profissionais. Esse pressuposto baseia-se na compreensão de que o trabalhador ou grupo de trabalhadores deve identificar e requerer a criação de espaços institucionalmente reconhecidos, bem como a aplicação de mecanismos capazes de apoiar a investigação e a potencialização das mudanças no agir profissional individual e grupal. A segunda presunção é relativa à concepção da relação entre o indivíduo e o coletivo. De acordo com Clot (2010), as situações conflituosas vividas no âmbito pessoal ou individual são estabelecidas pela agitação e discussão que emergem nas relações interativas entre os membros de uma coletividade humana. Essa conflituosidade social não é entendida de modo negativo por Clot que considera que os conflitos sociais ou externos à pessoa contribuem para que o indivíduo mobilize, moureje e coloque em movimento o seu psiquismo. Nesse sentido, é necessário que a autoconfrontação seja aplicada em todas as suas fases para que ocorram aproximações sucessivas e graduais na direção da produção de saberes pelos trabalhadores acerca do seu próprio ofício e, finalmente, a sua transformação por ação da coletividade profissional.

A autoconfrontação é percebida no universo teórico da Clínica da Atividade não apenas como um instrumento metodológico científico por meio do qual os pesquisadores realizam a recolha dos dados de uma investigação. Em verdade, tratase, primeiramente, de um procedimento de intervenção no trabalho de profissionais que pretendem analisar, ressignificar, compreender e, se possível, aprimorar ou transformar a atividade ocupacional da qual participam. Desse modo, os dados a serem recolhidos para a realização de uma pesquisa científica devem emergir do 
diálogo que se estabelece entre os próprios trabalhadores e destes com o especialista ou pesquisador durante a aplicação do dispositivo e, de modo privilegiado, no processo dialógico que se busca instalar na fase final da autoconfrontação, nomeada restituição ao coletivo de trabalho.

Considerando o contexto acima explicitado, foram delimitadas três questões articuladas e complementares que nortearam o exame e a discussão das dissertações e teses com uso da autoconfrontação produzidas pelos pesquisadores do grupo ALTER, a saber: a) quais são as semelhanças e diferenças na aplicação da autoconfrontação em estudos produzidos no ALTER comparativamente às prescrições de utilização desse dispositivo feitas pelos pesquisadores da Clínica da Atividade? b) Os estudiosos do grupo em tela desencadearam o seu trabalho partindo da demanda de profissionais pela análise das suas atividades ou os pesquisadores é que solicitaram a contribuição de trabalhadores nos processos de recolha de dados para as suas pesquisas? c) Por fim, caso não tenha havido demanda de trabalhadores, esse fato produziu alterações significativas no conjunto das fases de aplicação autoconfrontação e no resultado final alcançado?

A análise qualitativa do uso da autoconfrontação nas dissertações e teses do ALTER foi empreendida tomando-se como base a caracterização e as prescrições relativas à aplicação desse dispositivo feitas pelos pesquisadores da Clínica da Atividade. Destacamos que não compreendemos essa definição e descrição da autoconfrontação como modelo que deveria ter sido adotado pelos pesquisadores brasileiros na realização das suas pesquisas, visto que o contexto brasileiro diverge do europeu, mas apenas como referência prescritiva a partir da qual orientamos e desenvolvemos a nossa análise e discussão dos usos do dispositivo nas investigações do grupo ALTER, vinculado ao LAEL/PUC-SP, e liderado por Machado, entre 2002 e 2012.

Dessa forma, admitiu-se que os trabalhos de pesquisa que foram averiguados poderiam conter distinções, adaptações e avanços em relação às prescrições da Clínica da Atividade. Ainda, que essas distinções, hipoteticamente, representariam evoluções na utilização da autoconfrontação.

É necessário mencionar que a escolha do ALTER se justifica devido ao fato de esse grupo ter protagonizado o uso da autoconfrontação no campo da Linguística Aplicada no Brasil voltado ao trabalho docente na primeira década do século XXI, ao lado dos estudos realizados e orientados por Maria Cecilia Perez de Souza e Silva. Ainda, o grupo foi responsável ou esteve associado, entre 2002 e 2012, a metade das teses de doutorado ou dissertações de mestrado produzidas na área da Linguística Aplicada com uso desse dispositivo. No período citado foram concluídas 
dezessete teses e dissertações em Programas de Pós-Graduação em Linguística Aplicada do Brasil, de acordo com o estado do conhecimento sobre as aplicações da autoconfrontação elaborado por Messias e Perez (2013a), que considerou os dados organizados e tornados disponíveis pela Coordenação de Aperfeiçoamento de Pessoal de Nível Superior (CAPES) em seu banco de teses e dissertações, que reúne resumos de 125 mil trabalhos produzidos no país desde 1987.

Este artigo está organizado em três subseções, além desta introdução e das considerações finais, em que abordamos, sucessivamente: a) o contexto teórico de produção da autoconfrontação; b) as fases e movimentos de aplicação do dispositivo de acordo com as prescrições dos pesquisadores da Clínica da Atividade; c) exame e discussão sobre as aplicações da autoconfrontação nos trabalhos do ALTER.

\section{AUTOCONFRONTAÇÃO: CONTEXTO TEÓRICO DE PRODUÇÃO}

A autoconfrontação foi criada por Faïta (1997) para favorecer a intervenção e o estudo do trabalho de condutores de trens. $\mathrm{O}$ aprimoramento desse dispositivo tem sido realizado no contexto teórico da Clínica da Atividade, pela equipe do Laboratório de Psicologia do Trabalho do Conservatoire National de Arts e Metiers de Paris (CNAM), sob a coordenação de Clot.

A Clínica da Atividade se insere nas Ciências do Trabalho, especificamente no domínio da Psicologia do Trabalho e possui como raiz epistemológica a Psicologia Histórico-Cultural de Vigotski, segundo a qual o desenvolvimento psicossocial humano ocorre por meio do contato de cada sujeito com outras pessoas e grupos e do estabelecimento de processos colaborativos na mediação da transmissão dos saberes socialmente construídos. O pesquisador russo Vigotski (1926/2004) argumentava que a aprendizagem somente é efetiva quando se observa a apropriação dos saberes e a sua transformação em real desenvolvimento pelo sujeito.

De acordo com Clot $(2006 ; 2010)$, a perspectiva desenvolvimentista vigotskiana orienta a Clínica da Atividade na compreensão do trabalho, definido como experiência que permite ao homem metamorfosear o ambiente em que está inserido e, conjuntamente, desenvolver a si mesmo, em função do estímulo que o trabalho oferece à articulação entre a ação individual e a atividade coletiva, o que faz emergir e consolidar as capacidades de indivíduos e grupos. Trata-se de uma concepção ampliada de trabalho, reconhecido, portanto, por sua relevância

\footnotetext{
1 Neste trabalho optou-se por adotar a grafia Vigotski, conforme as traduções das obras do pensador
} russo para o português, realizadas por Paulo Bezerra. 
para a realização das potencialidades humanas, ao mesmo tempo em que, sob certas circunstâncias, pode-se constituir de dimensões capazes de conduzir à paralisia da ação, ao sofrimento e ao adoecimento do trabalhador.

É sob a inspiração de Vigotski que a Clínica da Atividade defende a definição do trabalho como um fenômeno social e psicológico. Além disso, compreende que os estudiosos da área do trabalho devem construir e acurar estratégias interventivas e metodológicas que permitam às pessoas e aos grupos experimentarem a possibilidade de transformação da própria realidade, a ampliação da sua vitalidade e sua potência de agir e a promoção de metamorfoses psicossociais. Nesse cenário, é possível compreender o lema transformar para compreender, adotado pela Clínica da Atividade, que evidencia a visão de desenvolvimento humano afastada das abordagens meramente biológicas e cognitivistas, a fim de enfatizar o monismo entre as dimensões afetiva, cognitiva e sociocultural na vivência concreta da construção das capacidades humanas e da transformação da vida.

Os métodos científicos e de mediação do desenvolvimento humano foram analisados por Vigotski (1927/1996) no texto Significado bistórico da crise da Psicologia: uma investigação metodológica, em que o autor sustenta que os métodos diretos de acesso ao real limitam o exame e a compreensão dos fenômenos psíquicos, permitindo somente o contato com as experiências humanas que são acessíveis diretamente pela observação de um pesquisador ou pela percepção da própria pessoa que vivencia o fenômeno, o que ocorreria, por exemplo, por intermédio da introspecção. Os analistas e pesquisadores da área do trabalho deveriam considerar, conforme a proposta de Vigotski (1927/1996, p. 283), que a "[...] necessidade de sair de uma vez por todas dos limites da experiência direta é assunto de vida ou morte [...]". Ainda conforme Vigotski, era necessário elaborar e desenvolver métodos indiretos de acesso ao psiquismo humano, capazes de favorecer aproximações sucessivas dos fenômenos psicológicos que possibilitassem considerar os comportamentos observáveis e os aspectos conscientes do homem analogamente aos métodos diretos, mas que também permitissem reconstruir e interpretar outras dimensões do psiquismo, não conscientes e subjetivas. $O$ surgimento e aperfeiçoamento da autoconfrontação, conforme concebido no âmbito da Clínica da Atividade, parece ter buscado atender ao chamado vigotskiano por meio da produção de instrumento interventivo e científico-metodológico cujo intento era, mediante a análise do trabalho pelo próprio trabalhador, favorecer o exame, a compreensão e a transformação ou desenvolvimento dos múltiplos elementos constituintes do psiquismo humano. 
Outro importante referencial para os pesquisadores da Clínica da Atividade, que possui relação com o modo como foi organizada a aplicação da autoconfrontação, é a Psicologia Social do Trabalho do italiano Oddone, o qual possuía forte sintonia com os movimentos sociais de trabalhadores do seu país, o que influenciou a produção das suas propostas teórico-práticas voltadas para o estímulo ao engajamento e compromisso do analista do trabalho e/ou do pesquisador com os coletivos de trabalhadores. Essa afinidade de Oddone (1986) com os coletivos organizados de operários contribuiu para a ênfase que conferia à necessidade de constante busca, por parte dos estudiosos do trabalho, pela redescoberta e ressignificação da subjetividade dos trabalhadores, valorizando a influência da atividade do coletivo de trabalhadores para cada pessoa engajada em uma atividade laboral determinada.

É possível indicar que a Clínica da Atividade incorporou à sua abordagem a compreensão de Odonne acerca dos aspectos subjetivos e afetivos que estão presentes no trabalho. Nessa perspectiva teórica cada trabalhador, para realizar a sua ação laboral, recolhe do coletivo de trabalhadores, dos representantes da hierarquia organizacional e, até da própria instituição em que está inserido, parte significativa de sua potência e dos seus recursos de trabalho. Segundo Clot (2010, p. 89) "[...] se esses recursos se esgotam [...] a vida psicológica de trabalho se encontra gravemente reduzida". Odonne $(1981 ; 1986)$ sugeriu que era necessário elaborar e desenvolver estratégias metodológicas voltadas para a ampliação do poder de agir e da capacidade dos trabalhadores de transformarem a própria realidade. Esta visão parece ter inspirado os pesquisadores da Clínica da Atividade a não apenas teorizar ou realizar pesquisas acadêmicas sobre o trabalho, mas criar ou aperfeiçoar ferramentas interventivas e de modificação de contextos laborais de pessoas e coletivos profissionais, como a autoconfrontação.

Vale mencionar que foi Oddone que ofereceu à Faïta e Clot os elementos teóricos que ensejaram a configuração da autoconfrontação como um dispositivo que organiza e integra múltiplos instrumentos interventivos e de pesquisa que devem ser usados, preferencialmente, em processos de transformação da atividade de coletivos laborais. Isso porque Oddone considerava que era preciso valorizar a experiência dos trabalhadores, integrando-os ao processo científico desde a recolha de dados até a validação dos achados de uma pesquisa. A partir desse pressuposto, o estudioso italiano desenvolveu o que denominou comunidade científica ampliada, que consistia na composição de um grupo, constituído pelos trabalhadores e pesquisadores, para a realização conjunta da coleta, exame e discussão dos dados de uma investigação. A comunidade científica ampliada deveria ter como objetivos: aproximar o estudioso e os trabalhadores; tornar os partícipes de uma pesquisa em 
cúmplices na construção de saberes sobre um ofício; estimular a apropriação, pelos trabalhadores, dos conhecimentos construídos ao longo da realização de um estudo acadêmico. A Clínica da Atividade aprimorou a concepção de Oddone, passando a nomeá-la comunidade ampliada de pesquisa, e incorporou à autoconfrontação a participação ativa dos trabalhadores nas múltiplas fases investigativas. Nesse sentido, o que se pretendeu foi garantir a compreensão, pelo coletivo profissional, dos aspectos caracterizadores, potencializadores e dificultadores do seu ofício e, prioritariamente, a apropriação pelos trabalhadores dos saberes produzidos durante a intervenção e pesquisa, de modo a subsidiar a possível transformação ou o aperfeiçoamento das tarefas e atividades ocupacionais desenvolvidas cotidianamente.

A realização de intervenções e pesquisas acadêmicas com o uso da autoconfrontação demandam do especialista ou pesquisador o conhecimento e domínio dos procedimentos constitutivos do dispositivo, de modo que se contribua com maior eficiência e eficácia para o surgimento do diálogo sobre um ofício específico e a transformação do processo laboral pelos próprios trabalhadores. Seguindo esse pressuposto, na próxima seção, apresentamos a caracterização da autoconfrontação e o conjunto de fases e movimentos que compõe a sua aplicação pelo pesquisador ou especialista.

\section{CARACTERIZAÇÃO, FASES E MOVIMENTOS DE APLICAÇÃO DA AUTOCON- FRONTAÇÃO}

Ressaltamos que será utilizada, preferencialmente, a palavra pesquisador para referir-se ao profissional responsável pela aplicação da autoconfrontação. Conforme é possível depreender da leitura das seções anteriores deste texto, sabemos que esse dispositivo é utilizado por psicólogos, especialistas ou analistas do trabalho em intervenções no cotidiano laboral, mas optamos por usar a nomenclatura pesquisador porque neste artigo pretendeu-se examinar e discutir os usos da autoconfrontação por estudiosos em investigações concluídas pelo ALTER (2002-2012), um grupo acadêmico-científico, conforme já apresentado em nossa introdução.

A autoconfrontação, de acordo com os estudos do dispositivo feitos por Messias e Perez $\left(2013 a_{i} 2013 b\right)$, que consideraram as prescrições dos estudiosos da Clínica da Atividade, se organiza em três fases articuladas e complementares entre si. Cada fase subdivide-se em movimentos distintos a serem seguidos pelo pesquisador. De acordo com Clot e Fernández (2007), a aplicação integral da 
autoconfrontação deve ocorrer em um ano e seis meses, sendo que cada uma das fases do dispositivo tem duração de seis meses.

\section{FASE A}

A primeira fase da autoconfrontação objetiva "[...] aproximar o pesquisador da atividade laboral e dos trabalhadores com os quais atuará ao longo do processo de intervenção e pesquisa" (MESSIAS, PEREZ, 2013a, p. 95). Trata-se de realizar um conjunto de ações que favoreça as aproximações sucessivas do estudioso em relação ao trabalho e ao coletivo profissional.

- Movimento 1 - Documentos prescritivos e contexto sociointeracional de trabalho

Este movimento tem como foco levar o pesquisador a conhecer o contexto sociointeracional de trabalho do coletivo laboral que está sendo analisado, por meio da identificação e exame dos documentos prescritivos do trabalho dos profissionais participantes da pesquisa ou processo interventivo. Ainda, é realizado o levantamento do histórico de produção desses documentos e quais os usos feitos pelos trabalhadores no cotidiano. Trata-se da aproximação da rotina dos trabalhadores e da coleta de informações sobre o seu métier.

- Movimento 2 - Observação e entrevista semiestruturada

O segundo movimento tem início com a composição de um grupo de trabalhadores voluntários, junto aos quais é obtida parte significativa dos dados. Os voluntários e o pesquisador compõem a comunidade ampliada de pesquisa (CLOT, 2010) que deve participar ativamente de todas as etapas seguintes da coleta de dados, do exame e do diálogo sobre o trabalho.

O pesquisador faz a observação do trabalho realizado pelos voluntários da pesquisa. Os aspectos relevantes testemunhados são registrados pelo pesquisador em um diário de pesquisas. Após a observação e registro, uma entrevista semiestruturada deve ser realizada com cada um dos trabalhadores para esclarecer dúvidas e detalhar informações obtidas na observação.

\section{FASE B}

A fase B subdivide-se em quatro movimentos distintos. Essa fase, conforme Messias e Perez (2013a, p. 96) "[...] tem como objetivo favorecer a análise do próprio trabalho por parte dos trabalhadores voluntários que compõem com o pesquisador a 
comunidade científica ampliada [...]" ou comunidade ampliada de pesquisa. É feito o registro do trabalho e sua análise de modo que os profissionais, por meio do diálogo sobre seu trabalho, tornem-se protagonistas da sua própria atividade laboral.

- Movimento 1 - Registro / Gravação da Atividade de Trabalho

Considerando as informações obtidas nas observações e entrevistas, o pesquisador realiza o registro da sequência de trabalho (gravada em áudio e vídeo) escolhida pelos participantes. Trata-se da obtenção de dados sobre o trabalbo real e/ ou real do trabalho (CLOT, 2006) que é o trabalho concreto, registrado no momento em que se desenrola a ação do trabalhador. $\mathrm{O}$ pesquisador busca captar momentos representativos do trabalho que é realizado cotidianamente.

- Movimento 2 - Seleção de trechos das atividades de trabalho registradas

Após a gravação das sequências de trabalho dos voluntários, o pesquisador seleciona trechos da ação de cada trabalhador. Estes trechos serão exibidos aos voluntários e orientarão o diálogo sobre o exercício que será realizado na fase seguinte, denominada autoconfrontação simples.

- Movimento 3 - Autoconfrontação simples

Neste movimento, cada trabalhador assiste aos trechos da gravação em áudio e vídeo, que foram previamente selecionados pelo pesquisador. Os dados a serem recolhidos são os comentários feitos pelo profissional acerca do seu próprio trabalho no momento em que assiste ao registro em áudio e vídeo. O pesquisador deve elaborar antecipadamente um roteiro de questões, visando organizar o diálogo com o voluntário da pesquisa. Geralmente, esse roteiro é composto por questões que permitirão ao trabalhador abordar os aspectos potencializadores e impeditivos ou dificultadores do seu agir profissional. Cumpre lembrar que nessa fase cada voluntário assiste ao seu vídeo com o pesquisador, isto é, o grupo de trabalhadores não vê os registros conjuntamente.

- Movimento 4 - Autoconfrontação cruzada

No último movimento da Fase B, o grupo de trabalhadores e o pesquisador assistem juntos aos trechos das gravações das atividades de trabalho. Trata-se da 
coleta de informações sobre o trabalho interpretado pelos voluntários da pesquisa. O pesquisador deve atuar como mediador do diálogo entre os trabalhadores sobre as sequências laborais registradas e visualizadas. $\mathrm{O}$ conjunto de movimentos que compõe a Fase B tem como objetivo:

[...] levar os trabalhadores a se interrogarem sobre o que eles observam da própria atividade. Em outras palavras, ele (o pesquisador) os convida a descrever o mais precisamente possível os gestos e as operações observáveis na gravação em vídeo até que se manifestem os limites dessa descrição, até que a verdade estabelecida seja flagrada na veracidade do diálogo, pela autenticidade dialógica. (CLOT, 2010, p. 240).

O que surgirá do processo de coleta será, muito provavelmente, um conjunto de reflexões sobre o trabalho e o agir profissional dos voluntários participantes da pesquisa. Isso porque, conforme foi mencionado anteriormente, a autoconfrontação favorece a vivência da dialogicidade profissional, em que emergem informações sobre os conflitos, as dissonâncias e as concordâncias sobre a atividade de trabalho.

\section{FASE C}

Essa fase é composta por um movimento denominado restituição ao coletivo de trabalho. É o momento em que as descobertas e considerações sobre o trabalho realizadas pelo pesquisador e pelos voluntários (comunidade ampliada de pesquisa) são regressadas ao coletivo de trabalhadores que atua na mesma função dos sujeitos do estudo. Essa submissão dos achados de pesquisa ao coletivo de trabalho tem como objetivo levar o conjunto de trabalhadores a se apropriar dos dados e análises da pesquisa, com vistas a estimular a ação engajada dos profissionais objetivando, segundo Clot (2010), a abertura de zonas de desenvolvimento potenciais, isto é, estimular a reflexão e a ação sobre as possibilidades de transformação da atividade laboral pelos próprios trabalhadores.

Nessa fase, o pesquisador planeja e realiza, em parceria com os voluntários que participaram das autoconfrontações, reuniões com o coletivo de trabalho. Essas reuniões podem acontecer com "[...] o coletivo profissional; o comitê de monitoramento da intervenção; o coletivo profissional ampliado, ou seja, o conjunto dos pares [...]" (CLOT, 2010, p. 241). Devem ser realizadas tantas reuniões quantas forem necessárias para que sejam criadas as condições para que os próprios trabalhadores façam o planejamento e a implementação de um plano de aperfeiçoamento ou transformação do seu processo laboral. 


\section{AUTOCONFRONTAÇÃO: USOS PELO GRUPO ALTER NO CAMPO DA LINGUÍSTICA APLICADA}

Nesta seção, são apresentadas e discutidas as pesquisas mais significativas realizadas pelo grupo ALTER em que foi utilizada a autoconfrontação. À maneira de introdução, é possível afirmar que este dispositivo, conforme as proposições de Faïta (1997), Vieira e Faïta (2003) e Clot (2006), começou a ser utilizado para a recolha de dados em pesquisas brasileiras da área da Linguística Aplicada (LA) na primeira década do século XXI, adaptada aos objetivos e contextos de produção de saberes em programas de pós-graduação stricto sensu. De acordo com Messias e Perez (2013a) as teses e dissertações da LA, em que foi utilizada a autoconfrontação, têm em comum o fato de se dedicarem à análise do trabalho por intermédio das práticas discursivas, textos e interações verbais produzidas nas diferentes etapas e movimentos do processo de aplicação da autoconfrontação junto aos trabalhadores de variados segmentos profissionais.

Inicialmente, as pesquisas que usaram a autoconfrontação buscavam produzir conhecimento sobre um determinado métier ou acerca das atividades profissionais de uma pessoa ou de um coletivo de trabalhadores. Esse foi o caso da primeira pesquisa acadêmico-científica da LA realizada no Brasil com uso da autoconfrontação, elaborada por Vieira (2002), que resultou na produção de tese defendida no Programa de Pós-Graduação em Linguística Aplicada e Estudos da Linguagem da Pontifícia Universidade Católica de São Paulo (LAEL/PUC-SP), orientada por Maria Cecília Pérez de Souza e Silva. Essa tese incidiu sobre uma situação de trabalho de médicos infectologistas com pacientes soropositivos e doentes de AIDS, mais especificamente, sobre o gênero da atividade da consulta clínica.

As duas pesquisas que se seguiram foram aquelas executadas por Menegolo (2005), uma dissertação de mestrado defendida no Programa de Pós-Graduação em Estudos da Linguagem, da Universidade Federal de Mato Grosso, sob orientação de Marcos Vieira, e a dissertação de Kayano (2005), defendida no âmbito do LAEL/PUC-SP. Estas duas pesquisas incidiram sobre o trabalho docente em dois contextos diferentes, sendo que Menegolo (2005) fez a análise linguística das interações verbais produzidas nas situações de trabalho de um grupo de professores designado para a correção de redações do exame vestibular de uma instituição de ensino superior do Estado do Paraná, no ano de 2004. E, Kayano (2005) realizou a primeira investigação que recaiu especificamente sobre o trabalho do professor de línguas e teve como objetivo averiguar como os prescritos institucionais influenciam na atuação do professor de língua inglesa do ensino superior em sala 
de aula, verificando de que maneira as autoprescrições dialogam com as prescrições institucionais.

A primeira investigação concluída no âmbito do grupo ALTER a utilizar a autoconfrontação foi a tese de doutorado de Lousada (2006), defendida no LAEL/PUC-SP, sob a orientação da professora doutora Anna Rachel Machado. Essa pesquisa, também, inaugurou, conforme concebido por Machado (2004), os contributos teóricos da Clínica da Atividade e do Interacionismo Sociodiscursivo (ISD), em especial no tocante à proposta metodológica de análise dos textos produzidos no e sobre o trabalho pelos sujeitos de uma pesquisa no processo de aplicação da autoconfrontação. Considerando as indicações dos pesquisadores da Clínica da Atividade é possível apontar que Lousada (2006) fez uso do dispositivo conforme o prescrito, mas de modo parcial ou fragmentado, tendo encerrado a sua aplicação na fase intermediária, que é a autoconfrontação simples. Essa pesquisa utilizou a autoconfrontação como instrumento de coleta de dados e teve um único trabalhador como voluntário da investigação. Ressalta-se que a pesquisa não partiu da demanda de um indivíduo ou coletivo de trabalhadores pela análise de uma situação laboral, mas sim, teve início na atuação profissional da própria pesquisadora (LOUSADA, 2006). O objetivo da pesquisa foi investigar o trabalho de um professor de francês, com ênfase para o exame dos aspectos prescritivos do trabalho e da sua manifestação real. Essa investigação não resultou num processo de (re)apropriação da atividade laboral pelo sujeito de pesquisa e seus pares durante o processo de investigação. Dito de outra forma, não foi prevista e efetivada a restituição dos achados do estudo ao coletivo de trabalho, de modo a estimular o processo de apropriação dos saberes produzidos na pesquisa pela coletividade profissional e, posteriormente, o início de uma possível transformação da atividade laboral pelos próprios trabalhadores.

Outra pesquisa com uso da autoconfrontação que foi relevante para o ALTER, foi aquela elaborada por Buzzo (2008), que teve seu doutoramento orientado por Machado no LAEL/PUC-SP. Nessa pesquisa, foi examinado um texto oral produzido conjuntamente por duas professoras de língua portuguesa, em situação de autoconfrontação cruzada, após a realização de uma atividade específica de trabalho (aulas que trataram do gênero diário de leitura), com o objetivo de investigar as representações sobre a docência construídas pelas duas participantes, bem como identificar as figuras interpretativas do agir do educador. A pesquisa de Buzzo, realizada como proposta de formação continuada, concluiu a fase intermediária de aplicação da autoconfrontação, mas não alcançou a etapa final dedicada à restituição ao coletivo de trabalho. A estudiosa indicou, de modo 
dissonante com as indicações da Clínica da Atividade, que não pretendia usar o dispositivo como meio para promover um processo de mediação que resultasse na transformação do trabalho.

O foco de Buzzo era verificar e discutir as reações das trabalhadoras voluntárias da pesquisa no processo de visualização da própria atividade laboral, que teve sequências gravadas em áudio e vídeo para posterior exibição para as professoras na autoconfrontação cruzada. A despeito de a tese de Buzzo não ter partido da demanda de profissionais pela realização de um processo interventivo e de produção de saberes sobre um ofício e, ainda, apesar de não ter realizado a restituição ao coletivo de trabalhadores, vale sinalizar que essa pesquisa, ao aplicar a autoconfrontação até a sua fase cruzada, apontou para os membros do ALTER e, em particular à sua líder, que era possível avançar nos estudos sobre o uso do dispositivo em situações de práticas linguageiras no e sobre o trabalho, as quais poderiam ser analisadas com aportes do ISD, bem como, vislumbrar a possibilidade de elaboração de proposituras para viabilizar a aplicação da autoconfrontação em estudos brasileiros que tivessem como resultado final o registro do aperfeiçoamento ou transformação do trabalho pelos próprios trabalhadores, conforme as indicações de Clot (2010). É importante destacar que Buzzo procurou reforçar os nexos e a complementaridade entre a Clínica da Atividade e o ISD. A Clínica da Atividade foi percebida no estudo de Buzzo como abordagem teórica que oferecia aportes para compreender o trabalho e que dispunha do dispositivo metodológico necessário para a recolha de dados. Já o ISD foi considerado como perspectiva teórica adequada para o exame dos textos no e sobre o trabalho recolhidos na aplicação da autoconfrontação, na medida em que situava a linguagem e a atividade linguageira como dimensões centrais para o entendimento do desenvolvimento e do trabalho humanos.

Esses trabalhos iniciais do ALTER influenciaram o desenvolvimento ulterior de investigações no campo da Linguística Aplicada em todo o país, os quais abordam especificamente as diferentes facetas do trabalho do professor, utilizando a autoconfrontação para a coleta de dados e o ISD para a análise dos textos obtidos em campo. Entre esses trabalhos, podemos mencionar: os estudos de Brasileiro $(2011$; 2012), sobre a formação docente e as relações interativas entre alunos e professores, ambos produzidos na Pontifícia Universidade Católica de Minas Gerais (PUC-Minas); a investigação de Rodrigues (2011) acerca das anotações de estagiários sobre o trabalho docente, realizada na Universidade Federal da Paraíba (UFPB); e a tese de Bortolini (2014), defendida na Universidade Federal de Santa 
Maria (UFSM), que pesquisou o agir docente representado em textos orais de professora vinculada a instituição militar.

No ano de 2008, o ALTER teve outra pesquisa concluída na qual foi aplicada a autoconfrontação, que foi a dissertação de Drey (2008), orientada por Ana Maria Guimarães, vice-coordenadora do grupo, no Programa de Pós-Graduação em Linguística Aplicada da Universidade do Vale do Rio dos Sinos (UNISINOS). Nessa dissertação, a autora verificou e caracterizou as representações sobre o agir docente por duas professoras de língua portuguesa do ensino médio de uma escola pública da região serrana do Rio Grande do Sul. Na pesquisa, foram analisados os diálogos produzidos pelas participantes durante a aplicação da autoconfrontação cruzada. No que diz respeito ao uso do dispositivo, pode-se indicar que tratou-se de uma pesquisa que apresentou as características típicas da apropriação e uso da autoconfrontação pelos estudiosos do ALTER, em que: a) não houve demanda, por parte de trabalhadores, para a intervenção no processo laboral e aplicação do dispositivo, conforme prescrito na Clínica da Atividade; b) os objetivos da investigação não contemplavam a promoção de mediações no sentido da interiorização dos saberes da pesquisa pelos trabalhadores, com vista ao início de um processo de aperfeiçoamento ou modificação do trabalho; c) a aplicação formal do dispositivo foi respeitada, comparativamente às indicações da Clínica da Atividade, não sendo observadas alterações no modo de uso da autoconfrontação.

Um estudo que se diferenciou no contexto do grupo de pesquisas foi a tese de Rodrigues (2010), orientada por Machado. A pesquisadora desenvolveu um exame de textos produzidos por dois professores universitários, em duas situações diferentes de coleta de dados, sendo um texto elaborado a partir do dispositivo metodológico instrução ao sósia e outro elaborado a partir da autoconfrontação simples. O objetivo geral não era apurar informações ou compreender o ofício de um grupo de profissionais, mas identificar as semelhanças e diferenças entre os procedimentos metodológicos de autoconfrontação e de instrução ao sósia. É importante esclarecer que o dispositivo denominado instrução ao sósia foi criado nos anos 1970 por Odonne (1981) e, analogamente à autoconfrontação, tem sido aperfeiçoado desde meados dos anos 1990 no quadro teórico-prático da Clínica da Atividade. A instrução ao sósia é um método indireto de acesso ao psiquismo humano em que o trabalhador descreve suas atividades a um pesquisador ou analista do trabalho, enquanto elas ocorrem. O que se pretende com o uso desse dispositivo é criar as condições para que o profissional fale sobre o seu trabalho, de modo a oportunizar a redescoberta ou reexame do ofício e, principalmente, a tomada de 
consciência dos aspectos constituintes, potencializadores e dificultadores de uma ocupação pelo próprio trabalhador.

No tocante à sua pesquisa, Rodrigues conjecturou que a aplicação da autoconfrontação tende a fazer emergir conteúdos considerados mais subjetivos e a instrução ao sósia, muito provavelmente, promove o levantamento de informações menos subjetivas. Consideramos que o estudo de Rodrigues foi relevante para apoiar os pesquisadores do grupo ALTER, em investigações ulteriores, especialmente, na escolha dos trabalhos em que seria mais apropriado fazer uso da autoconfrontação como dispositivo de recolha de dados. Novamente não houve demanda para a aplicação do dispositivo e, também, não estava entre os objetivos das ações da pesquisadora mediar a apropriação de conteúdos relacionados ao trabalho e a sua transformação por parte dos sujeitos da pesquisa.

Outro estudo com uso da autoconfrontação produzido no ALTER, sob a orientação inicial de Machado e co-orientação de Joaquim Dolz, professor da Universidade de Genebra, foi concluída em fins de 2012 e defendida no ano seguinte por Messias (2013), a qual examinou o agir do docente de Língua Portuguesa, levando em conta a perspectiva dos professores, mediados pela pesquisadora. Essa pesquisa resultou na elaboração teórica da noção de agir didático, compreendido como ações efetivadas pelos docentes relacionadas, especificamente, ao processo de ensino e aprendizagem. Vale ressaltar que, assim como Buzzo (2008), a pesquisadora realizou a sua investigação em contexto de formação continuada, e embora ela tenha feito praticamente todas as fases do procedimento de autoconfrontação (autoconfrontação simples, cruzada e constituição de um coletivo laboral), a restituição final ao grupo de trabalhadores não foi realizada durante a pesquisa. No que diz respeito à constituição do coletivo de trabalhadores, não houve demanda dos profissionais envolvidos, mas sim uma proposta de análise do trabalho da própria pesquisadora.

Vale relembrar que o exame das dissertações e teses do ALTER, as quais expusemos os casos mais significativos acima, foi realizado para nortear o debate sobre: as semelhanças e diferenças na aplicação da autoconfrontação em estudos produzidos no ALTER comparativamente às prescrições de utilização desse dispositivo pelos pesquisadores da Clínica da Atividade; identificar se os estudiosos do grupo em tela desencadearam o seu trabalho partindo da demanda de profissionais pela análise das suas pesquisas, conforme prescrições dos criadores e desenvolvedores do dispositivo, vinculados à Clínica da Atividade; e, caso não tenha havido demanda de trabalhadores, verificou-se se foram produzidas 
ou não alterações no conjunto das fases de aplicação autoconfrontação e/ou resultado final alcançado.

Considerando essas questões, é possível indicar que de modo geral os pesquisadores do ALTER seguiram, de modo instrumental, as prescrições de aplicação da autoconfrontação feitas por Clot $(2006 ;$; 2010), Faïta (1997) e Vieira e Faïta (2003) no quadro teórico da Clínica da Atividade. As adaptações ou modificações no uso do dispositivo responderam às conveniências e/ou imposições dos objetivos de cada pesquisa do ALTER, não tendo sido significativas de maneira a julgarmos que a autoconfrontação foi reconfigurada ou aperfeiçoada. A atividade investigativa acadêmica e o interesse dos pesquisadores desse grupo de pesquisa orientaram a opção pela utilização do dispositivo, o que conduziu, como resultado final, à produção de teses e dissertações, que visavam, inicialmente, à compreensão do trabalho enquanto atividade, mas não à análise e transformação da laboralidade pelos profissionais que participaram da autoconfrontação. Ainda, houve significativa redução no tempo de duração do processo de aplicação do dispositivo. Enquanto Clot e Fernández (2007) sugerem que cada uma das três fases da autoconfrontação tenha duração aproximada de seis meses, com a realização de numerosas sessões de análise da atividade laboral pelo pesquisador e os trabalhadores, no conjunto de pesquisas do ALTER a aplicação do dispositivo foi aligeirada e teve duração de apenas uma ou duas sessões por fase, justificada pelo tempo destinado ao desenvolvimento de uma dissertação ou tese. Ao final, no que diz respeito ao uso do dispositivo, o que se observou foi a sua fragmentação, na medida em que foi aplicado de modo parcial nas dissertações e teses concluídas nesse grupo, muito provavelmente, em função das especificidades de cada pesquisa. Nenhum dos estudos do ALTER, realizados entre 2002 e 2012, recaiu sobre a etapa de restituição ao coletivo de trabalhadores, que constitui-se no momento privilegiado de apropriação dos saberes produzidos na pesquisa pelos trabalhadores e início do processo de aprimoramento ou transformação do processo laboral.

É possível levantar numerosas hipóteses que podem auxiliar o entendimento da aplicação da autoconfrontação pelos pesquisadores do ALTER de forma fragmentada, aligeirada e sem a demanda de trabalhadores pela execução de intervenção nas suas atividades ocupacionais. Algumas delas que nos parecem mais pertinentes são:

- Devido a esse dispositivo metodológico ter sido utilizado em caráter experimental nas pesquisas iniciais do ALTER e ser adaptado e adequado à realidade de trabalho dos pesquisadores brasileiros, que raramente são demandados para intervir nos processos de trabalho. 
- O fato de ter-se adotado um dispositivo metodológico e analítico vindo de uma área do conhecimento (Psicologia) com maior tradição de intervenção em processos de trabalho que a LA.

- Ainda, em função de o grupo ALTER, no período aqui examinado, ter realizado trabalhos marcadamente acadêmicos, de modo que seus objetivos de pesquisas tem sido respondidas com o uso de apenas algumas etapas da autoconfrontação. Nota-se que o fato de não existir demanda de trabalhadores por transformação da atividade laboral torna a fase de restituição ao coletivo de difícil realização.

- O quarto motivo se relaciona ao tempo destinado ao desenvolvimento das pesquisas acadêmicas que resultam na produção de dissertações e teses no Brasil, que vão de dois a três anos no mestrado e quatro anos no doutorado. Isso faz com que o pesquisador não possa aguardar o surgimento de um grupo de trabalhadores que demande intervenção em seu cotidiano laboral. É preciso desenvolver a pesquisa e cumprir os prazos previamente determinados pela Coordenação de Aperfeiçoamento de Pessoal para o Ensino Superior (CAPES), que tende a enfatizar, no processo de avaliação dos programas de pós-graduação do país, o respeito ao período estabelecido para a conclusão das dissertações e teses, em detrimento do respeito às particularidades de cada pesquisa e dos possíveis benefícios gerados aos participantes dos estudos. A CAPES, ainda, não leva em conta o tempo que cada área ou subárea do saber acadêmico necessita para elaborar, realizar e concluir adequadamente os seus estudos, priorizando a homogeneização e quantificação dos critérios avaliativos da pós-graduação stricto sensu no país. Assim, parece razoável considerar a hipótese de que os pesquisadores do ALTER tenderam a prioriza a realização de seus estudos, em sintonia com as normas da CAPES, secundarizando a apropriação dos conhecimentos da pesquisa pelos trabalhadores com vistas à transformação da atividade laboral.

- O quinto motivo é a dificuldade em encontrar grupos de trabalho e instituições públicas ou privadas interessadas em participar da autoconfrontação em todas as suas etapas, visto que isto demanda grande disponibilidade institucional e por parte dos profissionais participantes.

- O sexto e último motivo, associado ao caráter experimental do dispositivo, é o fato que consideramos como um problema de transposição de método, ou seja, a dificuldade dos pesquisadores do ALTER no que se refere ao deslocamento para a LA brasileira de um dispositivo criado em outro país e por outra área de conhecimento (Psicologia).

Apesar das limitações, cumpre reconhecer que os estudos com uso da autoconfrontação produzidos no ALTER trouxeram contribuições ao campo 
científico do Brasil, em particular, no que diz respeito à integração interdisciplinar em um corpus teórico, metodológico e analítico de perspectivas ligadas à Psicologia e à Linguística Aplicada. Em síntese, os estudos com aplicação da autoconfrontação produzidos no grupo até 2012, sob a liderança de Machado, deixaram um importante legado tanto para a Linguística quanto para as Ciências do Trabalho, que consistiu da articulação original de diferentes áreas do saber e referenciais teóricos e metodológicos para a investigação do trabalho docente. Isto porque foi no processo de realização das pesquisas com a aplicação da autoconfrontação que o ALTER desenredou a questão do uso de aportes da Clínica da Atividade para compor a sua visão de trabalho, combinando essa perspectiva da Psicologia Social do Trabalho com os princípios e fundamentos do Interacionismo Sociodiscursivo, que foram aproximados pelos estudiosos do grupo, com vistas à elaboração, no âmbito da Linguística Aplicada, de uma proposta inovadora de recolha e análise de textos produzidos em situações de trabalho, com ênfase para a atividade linguageira dos professores.

\section{CONSIDERAÇÕES FINAIS}

À guisa de conclusão é necessário retomar que a autoconfrontação é um dispositivo elaborado para se caracterizar, simultaneamente, como um instrumento de análise, ressignificação e possível transformação do trabalho e, também, para ser uma ferramenta do campo acadêmico para a recolha e exame de dados sobre a atividade ocupacional de indivíduos ou grupos. Buscamos, desse modo, identificar e discutir as semelhanças e diferenças de aplicação do método da autoconfrontação proposta no âmbito da Clínica da Atividade em dissertações de mestrado e teses de doutorado realizadas por pesquisadores da Linguística Aplicada, o que foi realizado por meio do exame do caso particular de utilização deste dispositivo pelos estudiosos do grupo ALTER, vinculado ao LAEL/PUC-SP, que desenvolveu as suas atividades entre 2002 e 2012, sob a liderança de Anna Rachel Machado.

Considerando o exposto neste artigo, é preciso ressaltar que o ALTER realizou experiências significativas relacionadas à utilização da autoconfrontação como dispositivo metodológico científico. A despeito disso, é forçoso reconhecer a existência de uma lacuna no tocante ao uso da autoconfrontação de modo integral, enquanto mecanismo interventivo e de análise do trabalho capaz de apoiar coletivos de profissionais a se reapropriarem da sua própria atividade ocupacional. A experiência do ALTER, de fato, revelou-se como um esforço de adaptação da 
autoconfrontação ao contexto brasileiro, mas exclusivamente no tocante aos estudos acadêmicos, sintonizando o dispositivo com os prazos e exigências das pesquisas em Programas de Pós-Graduação do país. Ressaltamos que as pesquisas desse grupo focalizaram prioritariamente o exame da atividade de uma categoria profissional, os professores, o que resultou, de modo complementar, em importantes contribuições para o mundo acadêmico no que tange à noção de trabalho docente, compreendido como complexo, constituído por múltiplos artefatos e instrumentos ocupacionais (como estratégias de ensino, artefatos tecnológicos, documentos prescritivos e autoprescritivos) e influenciado por diferentes fatores externos ao contexto de sala de aula e ao próprio professor.

Por fim, as referências sobre a aplicação da autoconfrontação estritamente como instrumento científico, bem como a aproximação e articulação entre a Clínica da Atividade e o ISD, lideradas pelo ALTER, têm inspirado e influenciado o desenvolvimento de estudos sobre o trabalho docente por outros grupos de pesquisa em Linguística e Linguística Aplicada, reconhecidos pelo CNPq, e dispersos por universidades do país, tais como: grupo Linguagem e Educação, da Universidade Estadual de Londrina (UEL); grupo de Estudos e Pesquisa em Linguística Aplicada (GEPLA), Universidade Federal do Ceará (UFC); grupo Análise de Linguagem, Trabalho e suas Relações: aprendizagem, gêneros textuais e ensino, sediado na Universidade de São Paulo (USP) e Universidade São Francisco (USF); grupo Análise de Linguagem, Trabalho Educacional e suas Relações: gênero textual, Universidade Estadual de Londrina (UEL); Núcleo de Estudos Avançados em Linguagem, Interação e Tecnologias, da Universidade do Vale do Rio dos Sinos (UNISINOS).

\section{REFERÊNCIAS BIBLIOGRÁFICAS}

BORTOLINI, A. S. B. O. (2014). O agir docente representado na fala de uma professora do sistema de ensino militar. Tese de Doutorado em Letras. Faculdade de Letras, Universidade Federal de Santa Maria, Santa Maria.

BRASILEIRO, A. M. M. A. (2011). A Autoconfrontação simples aplicada à formação de docentes em situação de trabalho. Scripta, v. 15, nº 28, pp. 205-224.

BRASILEIRO, A. M. M. A. (2012). Emoção na sala de aula: impactos na interação professor/aluno/ objeto de ensino. Dissertação de Mestrado em Letras. Faculdade de Letras, PUC-Minas, Belo Horizonte. 
BUZZO, M. G. (2008). Os professores diante de um novo trabalho com leitura: modos de fazer semelhantes ou diferentes?. Tese de em Linguística Aplicada e Estudos da Linguagem. Faculdade de Letras, PUC-SP, São Paulo.

CLOT, Y. (2006). A função psicológica do trabalho, Trad. Adail Sobral, Petrópolis: Vozes.

CLOT, Y. (2010). Trabalho e poder de agir, Trad. João Freitas Teixeira e Marlene Machado Zica Vianna. Belo Horizonte: Fabrefactum.

CLOT, Y.; FERNÁNDEZ, G. (2007). Instrumentos de investigación: entrevistas en autoconfrontación: un método en clínica de la actidad. Laboreal, vol. 3, nº 1, pp. 15-19.

DREY, R. F. (2008). Eu nunca me vi, assim, de fora: representações sobre o agir docente através da autoconfrontação. Dissertação de Mestrado em Linguística Aplicada. Faculdade de Letras, UNISINOS, São Leopoldo.

FAÏTA, D. (1997). La conduite du TGV: exercices de styles. Champs visuels, nº 6, pp. 75-86.

KAYANO, L. M. D. (2005). A relação prescrito/real em sala de aula. Dissertação de Mestrado em Linguística Aplicada e Estudos da Linguagem. Faculdade de Letras, PUC-SP, São Paulo.

LOUSADA, E. G. (2006). Entre o trabalho prescrito e o realizado: um espaço para a emergência do trabalbo real do professor. Tese de Doutorado em Linguística Aplicada e Estudos da Linguagem. Faculdade de Letras, PUC-SP, São Paulo.

MACHADO, A. R. (org.) (2004). O ensino como trabalbo: uma abordagem discursiva. Londrina: Eduel.

MENEGOLO, L. W. (2005). Práticas discursivas no trabalbo de avaliar em vestibular: da atividade à constituição de sentidos. Dissertação de Mestrado em Estudos da Linguagem. Instituto de Ciências Humanas e Sociais, UFMT, Cuiabá.

MESSIAS, C. (2013). O agir didático do professor de língua portuguesa e sua reconfiguração em textos de autoconfrontação. Tese de Doutorado em Linguística Aplicada e Estudos da Linguagem. Faculdade de Letras, PUC-SP, São Paulo.

MESSIAS, C.; PEREZ, D. (2013a). A autoconfrontação e seus usos no campo da Linguística Aplicada ao estudo do trabalho do professor. Educação e Linguagens. v. 2, n⿳ 2, pp. 92-112. 
MESSIAS, C.; PEREZ, D. (2013b). O dispositivo metodológico e interventivo autoconfrontação e seus usos em pesquisas de Educação. Nuances. v. 24, n 3 , pp. 81-100.

ODDONE, I. (1981). Redécouvrir l'expérience ouvrière: vers une autre psychologie du travail?. Paris: Éditions Sociales.

ODDONE, I. et al. (1986). Ambiente de trabalbo: a luta dos trabalbadores pela saúde, Trad. Salvador Obiol de Freitas. São Paulo: Hucitec.

RODRIGUES, D. L. D. I. (2010). A autoconfrontação simples e a instrução ao sósia: entre diferenças e semelhanças. Tese de Doutorado em Linguística Aplicada e Estudos da Linguagem. Faculdade de Letras, PUC-SP, São Paulo.

RODRIGUES, M. A. N. (2011). As (re)configurações sobre o trabalbo docente em relatórios de estágio. Tese de Doutorado em Linguística. Faculdade de Letras, Universidade Federal da Paraíba, João Pessoa.

VIEIRA, M. (2002). A atividade, o discurso e a clínica: uma atividade dialógica do trabalbo médico. Tese de Doutorado em Linguística Aplicada e Estudos da Linguagem. Faculdade de Letras, PUC-SP, São Paulo.

VIEIRA, M.; FAÏTA, D. (2003). Quando os outros olham outros de si mesmo: reflexões metodológicas sobre a autoconfrontação cruzada. Polifonia, $\mathrm{n}^{\mathrm{O}}$ 07, pp. 27-65.

VIGOTSKI, L. S. (1927/1996). O significado histórico da crise da psicologia: uma investigação metodológica. In: Vigotski, L. S. Teoria e método em psicologia. Trad. Claudia Berliner. São Paulo: Editora Martins Fontes, pp. 203-420.

VIGOTSKI, L. S. (1927/1996). (1926/2004). Psicologia pedagógica. Trad. Paulo Bezerra. São Paulo: Editora Martins Fontes.

Recebido: 24/03/2015

Aceito: 28/08/2015 